\title{
Knowledge Based Educational Framework for Enhancing Practical Skills in Engineering Distance Learners
}

\author{
Venkatesh Chennam Vijay*, Mel Lees, Parmjit Chima, Craig Chapman, Pathmeswaran Raju \\ Faculty of Computing, Engineering and the Built Environment \\ School of Engineering, Design and Manufacturing Systems \\ Birmingham City University \\ Millennium Point, Curzon Street \\ Birmingham, UK. B4 7XG \\ *Venkatesh.Vijay@bcu.ac.uk
}

\begin{abstract}
This paper presents a concept of knowledge-based education (KBEd) framework and method in capturing, mapping, reusing and automating the knowledge of on-campus engineering laboratory instructor for imparting and assessing practical skills in engineering distance learners. The concept of distance learning in engineering science subjects like mechanical and automotive is still in its infant stage. As laboratory plays a vital role in engineering curriculum, delivering these programs and evaluating them have been the two major challenges for universities offering distance learning engineering courses. In order to overcome these challenges; an instructional system automated through experts knowledge with more granularity in monitoring the learners transition throughout the learning process is required.
\end{abstract}

Keywords-engineering laboratory; distance learning; tutor knowledge; knowledge capture; automation.

\section{INTRODUCTION}

The importance of practical experiment in the engineering course has significantly increased from the 19th century, as the mode of teaching shifted towards constructivist pedagogy, which emphasized the importance of knowledge through experience [1]. This was due to the increasing demand from the industries for engineering graduate equipped with theoretical knowledge and practical hands-on skills [2]. In university education, the concept of online learning has encouraged the participation level of learners who are physically away from on-campus environment, by providing them with improved access [3] [4]. The concept of distance learning in engineering science subjects like mechanical and automotive is still in its infant stage [5] [6], as laboratory environment plays a vital role in engineering curriculum for developing practical skills.

Teaching practical is different from teaching theory; in an educational domain learning practical skills are associated with lab instructor and workshop equipped with special equipment involving long blocks of time to practice or rehearse the technique [7]. The knowledge of the laboratory instructor plays an integral part in developing and assessing the practical skills of the learner. Where in distance-learning environment 'imparting practical experience' and 'assessing them' becomes two major challenges [8] [9]. Although, there are several new advancement in education through technology like "virtual/remote learning", one has to note that this has been extensively developed for disciplines like management and computer science, but are relatively underdeveloped in engineering science disciplines [10] [11].

As hands-on and know-how practical skills are critical for engineering disciplines, acquiring them from a distance learning mode turns-out to be a challenge. This research focuses on developing a method that captures and maps the oncampus tutors' knowledge into a framework in automating engineering virtual laboratory for enhancing the practical skills in distance learners. The proposed framework provides the environment, guidance and the assessment for the distance learners in practicing, learning and acquiring the practical skills. This paper presents a knowledge capture method in capturing on-campus tutors' knowledge with respect to procedure, product and diagnostics. Further explains how the captured knowledge are modelled and mapped into a knowledge-based educational (KBEd) framework for imparting and assessing the practical skill in a virtual environment.

\section{HISTORY OF ENGINEERING LABORATORIES}

In the past, engineering learning placed greater emphasis on practical work, engineers who graduated at that time were more practical oriented but lacked the underpinning theoretical concepts [12] [13]. Later the emphasis shifted more towards teaching theoretical concepts, which also let to an inconsistent learning outcome, since they lacked practical knowledge required for the industrial job. To overcome the above inconsistency, universities, industries and researchers constructed their own pedagogy [14] [15] [16]. For example: the Kolb [17] experimental learning theory, which helps in achieving the right balance between theory and practical skills. During the middle of nineteenth century universities like Cornell, Union college, Vale, MIT and many others emphasised laboratory instruction and practical experience for new-generations of engineers [18]. The first engineering taught course that involved practical aspects and fieldwork was from the American Society of Civil Engineers [19]. One of its early 
technical divisions was surveying, which provided a practical work environment [20]. Then laboratories and fieldwork were made mandatory for engineering education [21] [22]. Further the engineering accreditation process increased the quality of delivering engineering modules; these accreditations define a set of learning objectives that need to be achieved [23] [24]. The first among the engineering education accreditor was the American Institute of Chemical Engineers (AIChE) in 1925, and then followed by the Engineers Council for Professional Development (ECPD) in 1932, which is now known as ABET (Accreditation Board for Engineering and Technology) [25] [26]. In UK, the Engineering Council accreditation helps to ensure that the engineering education meets the world-class standard and helps them in acquiring industry-relevant skills. Fig. 1 provides the set of learning outcomes that needs to be achieved by the engineering student in UK in order to qualify as a professional engineer.

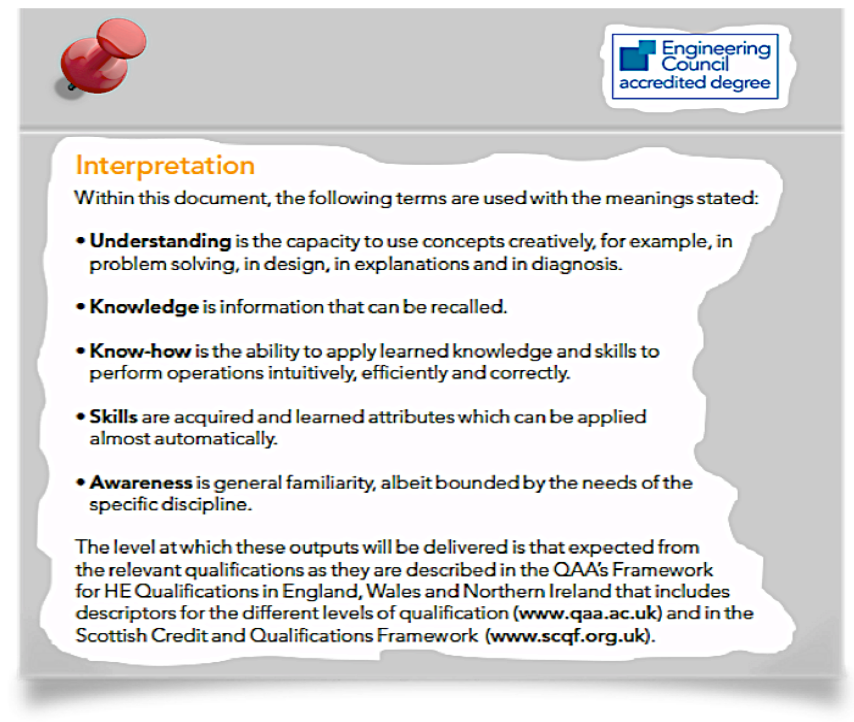

Fig.1. UK Standard for Professional Engineering Competence, Source: [27]

This research will focus mainly on the 'know-how' learning outcome, which is more on knowing how to perform hands-on activities in solving the problem. Hands-on experience is one of the fundamental skills required from an industry point-of-view [28]. Hands-on experience is more achievable on an on-campus environment compared to that of the distance-learning environment [29] [30]. As this 'know-how' practical skills in engineering courses like mechanical and automotive are set to be vital, imparting and assessing these practical skill turn out to be the two major challenge for the distance learning institutes [31] [32] [33] as the learners are spread around different geographical locations.

\section{A. Engineering Distance Learning}

During the past 200 years there has been number of revolution towards automation, mainly in three main sectors: agricultural, industrial and service sector [34]. The goal of automation is to reduce cost and increase efficiency, reusability and reliability. For automation, irrespective of the field there are three basic requirements that need to be satisfied: the availability of technology that replaces human, need for large number of similar items and low automation cost compared to that of traditional one [35]. At present, education sector are undergoing a revolution in automating instructional delivery using Intelligent Tutoring Systems (ITSs) at a minimal cost. In improving accessibility and achieving better learning outcomes by providing individualized learning experience as compared to traditional method involving teacher and classroom[36] [37] [38].

To date, engineering in distance learning mode uses three main approaches in teaching laboratory skills [39]. The first approach involves study centres, where the practical skills are imparted and assessed. Usual these test centres are Engineering College or Polytechnic those are located within assessable distance for the distance learners. Moreover, these centres are mostly not under full control of the distance education institute, hence the support or assessment carried out may not be up to the standard compared to that of the distance education institute's on-campus standard [40]. The second approach involves physical lab that provides remote access by using remote sensors known as remote labs. Remote lab is similar to traditional lab, they require space and physical equipment, and thus the cost of implementing and maintaining them are more or less the same as traditional lab. The characteristics that separate a remote lab form traditional one is the distance between the learner and the equipment in performing the experiment [41]. The third approach involves replacing physical laboratory by a digital software-based laboratory known as virtual labs. Where the virtual lab, which has been the latest, differs from the other two approaches through two distinguish characteristic: Here neither the equipment nor the environment exist in real, making the student and the equipment in no danger of being hurt or damaged [42]. In addition, apart from observing and performing practical task with the equipment students have the ability to visualize the internal mechanism of the performed task [43].

In an engineering education, development of subject knowledge along with practical skills is set to be vital, as these skills makes the student ready to undertake real world problem [44]. Engineering practical skills means physical hands-on skills required in performing activity using engineering equipment, tools and technique. In an on-campus environment, learning practical skills are associated with physical laboratory, equipment and lab instructor. Where, the laboratory instructor is the source of knowledge for the students in explaining and demonstrating the experiment and assesses their performance in providing feedback to them [45] [46]. Different practical skills taught have different complexity level and require varying level of knowledge in executing them (Fig.2). Apart from that, learning these practical tasks also depends upon the learning style of each individual. For instance: some students may be tentative in grasping and acquiring the practical skills with few iteration and some may observe, analyse and repeat several times before achieving it. In a traditional environment the lab instructor alters the procedure and the teaching style depending upon the complexity of the task and provides feedback for each individual in improving their practical skill [47]. When it comes to delivering these in a virtual environment it becomes complex, as the learner and teacher are physical separated from each other. Although with the use of new technology like virtual/remote laboratories, teaching and assessing can be 
automated by capturing the knowledge from the instructor. But these captured knowledge have to be mapped to the right rules in provide right feedback.

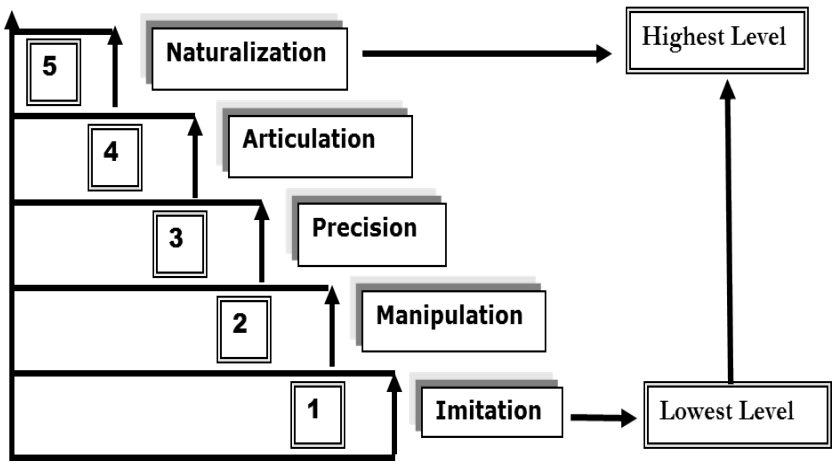

Fig.2. Taxonomy of psychomotor domain, Source: [48]

\section{B. Remote and Virtual Laboratoties}

There are several remote and virtual laboratories in the literature [49] [50] [51] [52]. The Situation Engine [53] at The University of New South Wales, iLab [54] at Massachusetts Institute of Technology, Advance Science and Automation Corp. (ASA) [55] [56] at US, Lab-Share [57] at Curtin University and the WebLab- DEUSTO [58] at University of Deusto, are important virtual/remote laboratories. Apart from that [59] companies have developed virtual environment to learn practical skills through latest technology like "Haptic" in providing a better hands-on experience. In [60] the authors provide the present benefits and challenges of virtual learning environment. In [61] the authors provide the literature review for characteristics of the next generation of remote laboratories, in [62] study provides assessment model for present virtual laboratories by adapting Felder and Silverman in generating customized learning objects for different learning styles. In [63], after an overview on the historical role of engineering instructional laboratory presents the coherent learning objectives for modern laboratories and development for future research, in [64] [65] [66] studies provide the challenges in the current virtual/remote laboratory environment. All these study highlights the need for enchantment in imparting and assessing the practical skill among the engineering distance learners.

It is clear that, there are several virtual/remote-learning frameworks that assess the student knowledge and learning preferences and provide them a customized learning path. In addition to that, there are few frameworks, which are capable of providing dynamic learning path by performing the assessment check at the end of each learning outcome. However, this study is not about critically reviewing these ideas or technologies, but to possibly generalize and extent these ideas in enhancing the practical learning outcome by improving the teaching and assessing system in a virtual environment. Having said that, not many researchers have explored in providing much granularity for imparting and assessing the engineering distance learners by exactly identifying what and where the students have gone wrong and provide them with appropriate assistant in learning the practical skill. In a traditional environment the laboratory instructor is able to provide the students with much granularity in the feedback by observing the students' performance. The granularity is achievable in a virtual environment by constantly monitoring the learner's transition throughout the learning process by an artificial intelligent (AI) system, automated through the knowledge and rule captured from engineering laboratory experts. Additionally, there isn't any defined method on how to capture knowledge from laboratory instructors in automating the instructional design for engineering practical learning. This study aims to provide a knowledge-based educational (KBEd) framework and method that adds value in imparting and assessing practical skills for engineering distance learning students in a virtual environment. The rest of the paper will discuss in detail on how the knowledge from the engineering laboratory instructor is captured and mapped into the framework for automation.

\section{USE CASE}

This study uses Birmingham City University, UK as the case organisation in validating the proposed method and framework. The case organisation runs mechanical engineering course, where first year students learn several fundamental practical tasks related to the subject (Table I).

TABLE I. LIST OF PRACTICAL TASKS FOR FIRST YEAR ON-CAMPUS ENGINEERING STUDENTS

\begin{tabular}{|l|l|}
\hline \multicolumn{1}{|c|}{ Topic } & \multicolumn{1}{|c|}{ Practical Task Taught } \\
\hline Applied Mechanics & Strain gauge application on beam \\
& E by Bending of Aluminium beam \\
& Bending Stress of beam \\
& Damped Vibration of beam \\
& Photo-stress experiment \\
& Boundary Stress of Beam \\
\hline Materials and Manufacture & Metal joining exercise - \\
& manufacturing and programming on \\
& CNC machine \\
& Metal joining exercise - Tensile \\
& testing on Testometric machine \\
& Tensile testing of Carbon steel \\
& materials and microstructures \\
& Corrosion of Metals \\
& Creep test \\
& Basic Welding \\
\hline Thermodynamics & Heat exchangers \\
& Temperature calibration \\
& Engine Test cell demo \\
\hline
\end{tabular}

Among these taught practical task, basic welding is not part of the real academic assessment and does not influence the academic score of the student, which was selected as the case study in testing the framework. Although the welding task was not part of the main assessment, the acquired skill was vital for their third year practical work, where the students team up in building a student formula car. The case organisation's laboratory instructor, where students observe and practice in acquiring the skill, taught how to perform a basic welding safely. This task consists of four learning topics: health and safety, flat plate welding, t-joint welding and saucer welding. At first the laboratory instructor guides them through the health and safety procedures, followed by a brief introduction about the tools and equipment required for the task. In addition, the instructor pauses and clears the doubts for the students during his explanation. Then the instructor shows how to weld two flat plates, while performing welding the instructor pauses and provides information about the key checks that needed to be 
carried out. After observing how to execute flat plate welding, students have-a-go at it while the instructor monitors them by creating a checklist in this mind and observers their action against it, in providing relevant feedback. The students then have-a-another go, in avoiding the mistakes that they have committed in the previous attempt, once the students have completed the task, the instructor demonstrates how to execute a t-joint welding, followed by a demonstration for saucer welding. To automate the above instructional system in a virtual environment, the knowledge from the laboratory instructor need to be captured.

\section{A. Knowledge capture from laboratory instructor}

The proposed method for capturing knowledge from the laboratory instructor adapts knowledge-based engineering techniques that are been applied in manufacturing industries for capturing knowledge from the concern experts in automating the system [80] [81]. The value of knowledge-based engineering lies in the way the captured data and rules are mapped to a greater granularity through classes and sub-classes. The knowledge from on-campus tutor (in this case they are mostly lab instructors) where captured through a knowledgebased engineering method, which was adapted and modified according to the research scope (Table II). The first column refers to the sequence of procedure that needs to be carried out while executing the practical task; the second column refers to the aesthetics of the product corresponding to the procedure and the third column refers to the knowledge in providing what could have possibly gone wrong. The process of knowledge capturing started with a semi-structured interview in gathering the data for procedural and product requirement (column 1\&2) for each taught task followed by the possible diagnostics (column 3). The gathered data were then filled in the respective column (Table III), for a set of sequence or a single sequence has a corresponding product check that needs to be made. For the chosen practical task (Welding) there are three different product checks: soft-check, hard-check and self-check. The soft-check and the hard-check are performed by the tutor, whereas the self-check is to be performed by the learners. Learners, who fail to meet the product check for the performed procedural sequence, will be diagnosed by the tutor in capturing what could have possibly gone wrong by mapping them to the appropriate diagnostic knowledge.

TABLE II. KNOWLEDGE CAPTURE TEMPLATE

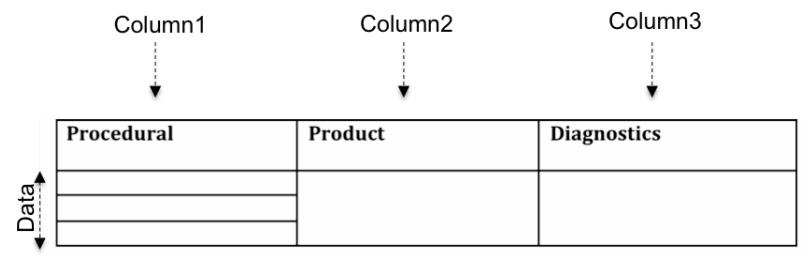

TABLE III: KNOWLEDGE CAPTURE TEMPLATE WITH GATHERED DATA (TASK $>$ FLAT PLATE WELD)

\begin{tabular}{|c|c|c|}
\hline Procedural & Product & Diagnostics \\
\hline $\begin{array}{l}\begin{array}{l}\text { Select your metal } \\
\text { plate }\end{array} \\
\text { Degrees the plate } \\
\text { Remove any burns } \\
\end{array}$ & $\begin{array}{l}\text { Soft-check: 'Check } \\
\text { the selection of plate } \\
\text { and whether the plate } \\
\text { is cleaned' }\end{array}$ & $\begin{array}{l}\text { Lack of fundamental } \\
\text { knowledge }\end{array}$ \\
\hline $\begin{array}{l}\text { Position the plate } \\
\text { Hold it with magnets }\end{array}$ & $\begin{array}{l}\text { Soft-check: 'Check } \\
\text { whether the magnet } \\
\text { positioned proper' }\end{array}$ & $\begin{array}{l}\text { Lack of preparation } \\
\text { knowledge }\end{array}$ \\
\hline $\begin{array}{l}\text { Setup the equipment } \\
\text { \& safety measures: } \\
\text { Personal protection } \\
\text { (app) } \\
\text { Safety equipment } \\
\text { (app): Overalls: Apron } \\
\text { Gloves: Light duty } \\
\text { Mask: Both } \\
\text { Footwear: Both } \\
\text { How to use Safety } \\
\text { equipment: (app) } \\
\text { How to check Safety } \\
\text { equipment: (app) } \\
\text { Other people } \\
\text { protection (app): } \\
\text { Safety equipment } \\
\text { (app): both } \\
\text { How to check the } \\
\text { standard: both } \\
\text { Equipment protection } \\
\text { (app): } \\
\text { Mig: } \\
\text { Set the amps - } \\
\text { depends of think of } \\
\text { the metal he uses } \\
\text { (1.6mm) - setting } 3- \\
\text { about } 60-80 A m p s\end{array}$ & $\begin{array}{l}\text { Hard-check: 'Check } \\
\text { for appropriate setup } \\
\text { and safety' }\end{array}$ & $\begin{array}{l}\text { They can't proceed to the } \\
\text { next step if safety } \\
\text { measures are not satisfied } \\
\text { (if failed - will generate } \\
\text { immediate learning } \\
\text { object), } \\
\text { Wrong setup of volt will } \\
\text { impact on other task and } \\
\text { output }\end{array}$ \\
\hline Tack weld the corner & \multirow[b]{2}{*}{$\begin{array}{l}\text { Self-check: 'Check } \\
\text { corner edge, try to } \\
\text { pick it up - the two } \\
\text { pieces should stay } \\
\text { together, after taking } \\
\text { out the magnet. }\end{array}$} & \multirow[b]{2}{*}{$\begin{array}{l}\text { Improper weld } \\
\text { (Disarrangement } \\
\text { magnet) } \\
\text { (Wrong angle of the torch) } \\
\text { Not cleaned the plate } \\
\text { properly } \\
\text { Impact on other task and } \\
\text { output. }\end{array}$} \\
\hline Remove the magnet & & \\
\hline $\begin{array}{l}\text { Weld from outside to } \\
20 \mathrm{~mm} \text { inside }\end{array}$ & $\begin{array}{l}\text { Self_check: 'Check } \\
\text { for gap or bend on the } \\
\text { plate' }\end{array}$ & $\begin{array}{l}\text { Improper weld } \\
\text { (Wrong angle of the torch) } \\
\text { (Not selected the right } \\
\text { amps) } \\
\text { Cause of improper tack } \\
\text { weld } \\
\text { Impact on other task and } \\
\text { output }\end{array}$ \\
\hline Main middle welding & \multirow[b]{2}{*}{$\begin{array}{l}\text { Backend check: } \\
\text { 'Check for nice and } \\
\text { flat welded plate, } \\
\text { Other side of the pate } \\
\text { for depth of } \\
\text { penetration. }\end{array}$} & \multirow[b]{2}{*}{$\begin{array}{l}\text { Inaccurate execution of } \\
\text { welding skills(Wrong } \\
\text { angle of the torch) } \\
\text { Amps to low or high } \\
\text { Lack of penetration of } \\
\text { tack weld (plates move } \\
\text { apart) }\end{array}$} \\
\hline Scrape the excess & & \\
\hline
\end{tabular}

\section{B. Knowledge modelling using ontology}

The gathered data were stored under an ontological structure through classes and sub-classes consisting of learning object, learning structure, learning mode and assessment. In this case study, we have one learning object 'Welding' which consist of three sub-learning objects: flat plate welding, t-joint 
welding and saucer welding which encapsulates learning structure, learning mode and the assessment applicable to it. The applicability is provided by the rules that are been assigned to each of the sub-learning objects, which maps them to its appropriate content under learning structure, learning mode and assessment (Fig. 3). Learning structure consists of three subclasses: Introduction, Preparation and Execution and Evaluation. Under Introduction fundamental information like, overview about the practical task, relevant procedures, tools, health and safety were stored. Preparation consist of information about how to set-up the required equipment. Execution\&Evaluation provided information on how to perform and test the output of the task. The learning mode consists of three sub-classes: Tell me, Show me and Have-aGo, which were mapped to their respective assessment. The data from Table III where stored under the assessment, which consists of three sub-classes: Procedural, Product and Diagnostics. Procedural sub-class consist the sequence of procedures required to perform a task. The output achieved through the performed procedure is monitored by the Product sub-class, which consist information to check whether the output-achieved satisfies the required aesthetics. Diagnostics sub-class consists of knowledge in what could possibly go wrong and why.

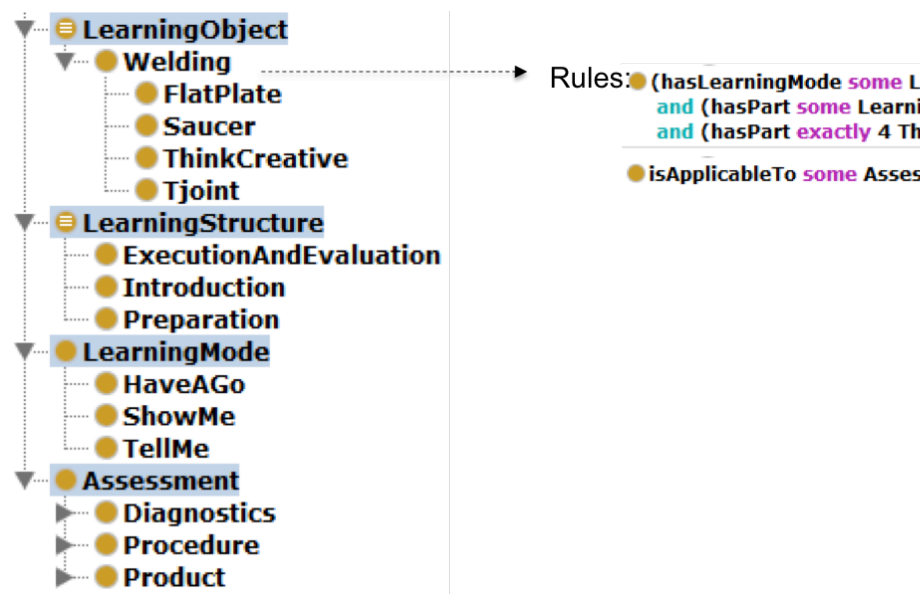

Fig. 3. Arrangement of gathered data under class and sub-class with assigned rules

\section{KNOWLEDGE-BASED EDUCATIONAL FRAMEWORK (KBED)}

The proposed KBEd framework (Fig. 4) consists of three major blocks: The Artificial intelligent (AI) Tutor, Environment and the Assessment. The AI Tutors and Assessment block provide the automation for imparting and assessing the practical skill, the environment block provides the virtual laboratory environment where the students practice their skill. The captured knowledge that is classified under ontological structure through classes and sub-classes (Fig. 3) is stored in AI Tutor block under the Knowledge-Engine (KE) and its respective rules were stored under the Mapping- Engine (ME). The Learning-Object-Engine (LOE) in AI Tutor generates the learning objects that are required for the learners through Generate-Learning-Object algorithm (GLOa) by calling the classes and rules mapped to it. These generated learning objects are visualized through the Run-Time-Engine (RTE) under the Environment block, which provides the applicable learning modes: Tell-Me (TM), Show-Me (SM) and Have-a-Go (HG), where, the student learns by seeing, listening and by doing the task. Learner's performance and preference are captured by the Student-Engine (SE) under Assessment block in generating their individual portfolio. The AssessmentEngine (AE) assesses the learner's performance and provides feedback, which is considered to be the backborn of the proposed framework. The feedback system is automated though Level, Depth and Rigour axis algorithm (ADRa), where, the level represents the complexity of the task that the learner is performing, the depth represents the depth of knowledge that the learner has to impart in executing the task and the rigour represents the measuring scale. The concept of ADRa is the extension of Hess cognitive rigor matrix, which suggests two axes: the level and the depth in measuring student's performance. This study, in the course of automating the assessment process has added rigour as the third axis in assessing the performance of the students. The output from the assessment-engine is sent to output unit in triggering the next learning objects required for the learner from the LOE. Unknown sequence or learners actions that are not part of the AI's knowledge are captured as new instances, which could possible turn as a new knowledge.

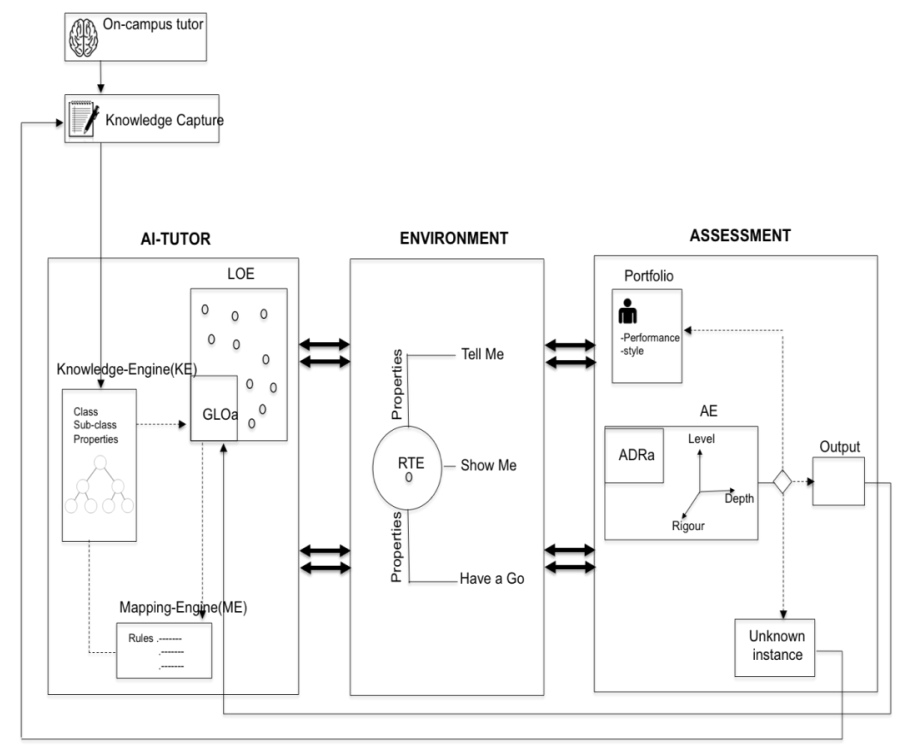

Fig. 4. KBEd framework

\section{Discussion}

The distance learners visualizes and practice their welding skills in the Environment, this study used UNITY3D game development software in creating a virtual laboratory (Fig. 5 (a)\&(b)). The action or a query that has been instantiated by the learner in the Environment is guided, monitored and assessed by the AI Tutor through the captured rules and knowledge that are encapsulated under the learning objects. For example, in the virtual environment distance learners who are intended in learning how to welding are provided with the learning objects associated under welding (Fig. 5 (c)\&(d)), where, they interact with these learning objects in practicing different welding task. 
Learner's transition is monitored and assessed by the AI Tutor through the procedural, product and diagnostics class in achieving much granularity in imparting and assessing the practical skill in a virtual environment. A detail discussion on how the AI Tutor communicates and captures the learner's actions that take place in the Environment will be presented in the future work. The method that is been proposed in capturing the knowledge from laboratory instructor through a three column approach, provide a simple and efficient way in gathering and classifying tutors knowledge under classes and subclass in automating the instructional system for a virtual environment. Further, the knowledge capture template provides a clear view on the data that needed to be gathered in order to build an AI Tutor in imparting and assessing the practical skills of the distance leaners in a virtual environment. The virtual laboratory build on the proposed framework will be tested with the case organisations first year mechanical engineering students in enhancing the performance of the proposed framework.

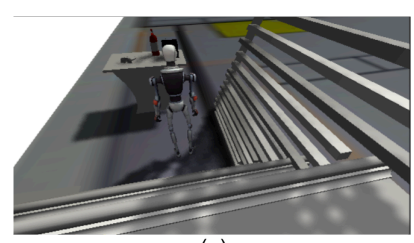

(a)

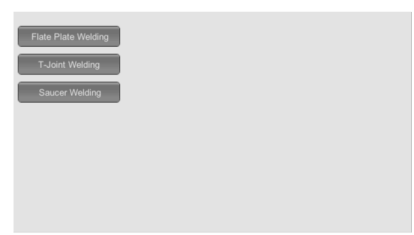

(c)

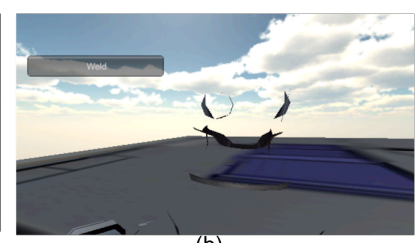

(b)

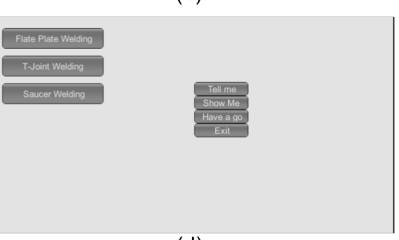

(d)
Fig. 5. The Environment developed in Unity3d

\section{CONCLUSION}

In engineering education laboratory know-how skills is set to be one of the primary learning outcomes, imparting and assessing them turn up to a major challenge for engineering distance learning providers. Although there are several advancements in engineering distance learning such as virtual/remote laboratories, no significant work has been carried out for providing much granularity in imparting and assessing the distance learners in a virtual environment. In order to achieve this, tutors knowledge has to be captured, and mapped for automating them in a virtual environment. This paper has presented a knowledge capture method in capturing tutors knowledge with respect to procedure, product and diagnostics. Further it provided a knowledge-based educational (KBEd) framework and explained how the captured data from a case study are modelled, mapped and automated for providing greater granularity in imparting and assessing the practical skill in a virtual environment. This work has demonstrated how the knowledge from an on-campus tutor could be captured and represented in an ontological structure in automating an AI tutor for virtual environment. The future work includes the further development of the AI tutor, assessment mechanism and the virtual environment.

\section{REFERENCES}

[1] Feisel, Lyle D., and Albert J. Rosa. "The role of the laboratory in undergraduate engineering education." Journal of Engineering Education 94.1 (2005): 121-130.

[2] Corter, James E., et al. "Constructing reality: A study of remote, handson, and simulated laboratories." ACM Transactions on Computer-Human Interaction (TOCHI) 14.2 (2007): 7.

[3] Xiao-liang, Zhu, and Liu Quan. "Architecture of Integrated Education Service Platform for E-Learning in Rural Area." Computer Network and Multimedia Technology, 2009. CNMT 2009. International Symposium on. IEEE, 2009.

[4] Barbour, Michael K., and Thomas C. Reeves. "The reality of virtual schools: A review of the literature." Computers \& Education 52.2 (2009): 402-416.

[5] Perry, W., et al. "Grand challenges for engineering." National Academy of Engineering, Washington, DC (2008).

[6] Anis, Hussein. "E-learning in engineering education-General challenges and the Egyptian experience." (2011).

[7] Ma, Jing, and Jeffrey V. Nickerson. "Hands-on, simulated, and remote laboratories: A comparative literature review." ACM Computing Surveys (CSUR) 38.3 (2006): 7.

[8] Peterson, G.D. and Feisel, L.D. “ e-Learning: The Challenge for Engineering Education', ECI Conference on e-Technologies in Engineering Education". Learning Outcomes Providing Future Possibilities, Davos, Switzerland (2002).

[9] Wu, Wen-Hsiung, et al. "Development and Assessment of WSISLE-CNC for Engineering Education." The World Congress on Engineering and Computer Science (2008).

[10] Murphy, Elizabeth, and María A. Rodríguez Manzanares. "Contradictions between the virtual and physical high school classroom: A third generation Activity Theory perspective." British Journal of Educational Technology 39.6 (2008): 1061-1072.

[11] Rajaei, Hassan, and Arwa Aldhalaan. "Advances in virtual learning environments and classrooms." Proceedings of the 14th Communications and Networking Symposium. Society for Computer Simulation International, 2011.

[12] Roth, Wolff Michael. "Experimenting in a constructivist high school physics laboratory." Journal of research in Science teaching 31.2 (1994): 197-223.

[13] Hofstein, Avi, and Vincent N. Lunetta. "The laboratory in science education: Foundations for the twenty first century." Science education 88.1 (2004): 28-54.

[14] Committee of College and University Examiners. Taxonomy of educational objectives. Vol. 1. New York: David McKay, 1956.

[15] Loo, Robert. "Evaluating change and stability in learning style scores: a methodological concern." Educational Psychology 17.1-2 (1997): 95-100.

[16] Newton, Sidney. "A Situation Engine for Teaching and Learning Residential Construction Technology." Proceedings of ASC Annual Conference. 2012

[17] Kolb, David A. Learning-style inventory: Self-scoring inventory and interpretation booklet. TRG Hay/McBer, 1985.

[18] Bisantz, Ann M., and Victor L. Paquet. "Implementation and Evaluation of a Multi course Case Study for Framing Laboratory Exercises." Journal of Engineering Education 91.3 (2002): 299-307.

[19] Felder, Richard M., and Rebecca Brent. "Designing and teaching courses to satisfy the ABET engineering criteria." Journal of Engineering Education 92.1 (2003): 7-25.

[20] Kamis, Arnold, and Heikki Topi. "Network Subnetting: an Instance of Technical Problem Solving in Kolb's Experiential Learning Cycle." System Sciences, 2007. HICSS 2007. 40th Annual Hawaii International Conference on. IEEE, 2007.

[21] McGourty, J.M., Shuman, L.J., Besterfield-Sacre, M., Atman, C.J., Miller, R., Olds, B., Rogers, G., and Wolfe, H. "Preparing for ABET EC2000: Research-Based Assessment Methods and Processes". International Journal of Engineering Education. 18 (2), (2002): 157-167. 
[22] Wankat, Phillip C. "Analysis of the first ten years of the Journal of Engineering Education." Journal of Engineering Education 93.1 (2004): $13-21$.

[23] Grinter, L.E. "Report of the Committee on Evaluation of Engineering Education". Journal of Engineering Education. 45, (1955): 25-60.

[24] Stephan, Karl D. "All this and engineering too: a history of accreditation requirements." Technology and Society Magazine, IEEE 21.3 (2002): 815.

[25] Reynolds, Terry S., and Bruce E. Seely. "Striving for balance: A hundred years of the American Society for Engineering Education." Journal of Engineering Education 82.3 (1993): 136-151.

[26] Carlson, Bruce, et al. "A Motivational First year Electronics Lab Course."Journal of Engineering Education 86.4 (1997): 357-362

[27] Engineering Council. "The Engineering Accreditation Board (EAB)", [ONLINE] Available at:http://www.engc.org.uk/education-skills/accreditation/engineering-accreditation-board. (2013): [Accessed 03 November 14]

[28] Wojciechowski, Rafał, and Wojciech Cellary. "Evaluation of learners' attitude toward learning in ARIES augmented reality environments." Computers \& Education 68 (2013): 570-585.

[29] Al-Samarraie, Hosam, Timothy Teo, and Merza Abbas. "Can structured representation enhance students' thinking skills for better understanding of E-learning content?." Computers \& Education 69 (2013): 463-473.

[30] Fabregas, Ernesto, et al. "Developing a remote laboratory for engineering education." Computers \& Education 57.2 (2011): 1686-1697.

[31] Aguilar, R., et al. "Fuzzy and MultiAgent Instructional Planner for an Intelligent Tutorial System." Applied Soft Computing 11.2 (2011): 2142 2150.

[32] Vidal-Castro, Christian, Miguel-Ángel Sicilia, and Manuel Prieto. "Representing instructional design methods using ontologies and rules." Knowledge-Based Systems 33 (2012): 180-194.

[33] Bennett, Sue, and Lori Lockyer. "Becoming an online teacher: Adapting to a changed environment for teaching and learning in higher education."Educational Media International 41.3 (2004): 231-248.

[34] Wu, Ying-Han, and Heiu-Jou Shaw. "Document based knowledge base engineering method for ship basic design." Ocean Engineering 38.13 (2011): 1508-1521.

[35] Freiberg, Martina, Albrecht Striffler, and Frank Puppe. "Extensible Prototyping for pragmatic engineering of knowledge-based systems." Expert Systems with Applications 39.11 (2012): 10177-10190.

[36] Zvonov, Valery, Viacheslav Kulagin, and Alexander Mezhenin. "New Technologies in E-learning and Creative Pedagogic in Continuous Engineering Education." (2008)

[37] Wenger, Etienne. "Artificial intelligence and tutoring systems." (1987).

[38] Corbett, Albert T., Kenneth R. Koedinger, and John R. Anderson. "Intelligent tutoring systems." Handbook of humancomputer interaction (1997): 849-874.

[39] Tait, Alan. "Planning student support for open and distance learning." Open learning 15.3 (2000): 287-299.

[40] Bates, AW Tony. Technology, e-learning and distance education. Routledge, 2005.

[41] Gravier, Christophe, et al. "State of the art about remote laboratories paradigms-foundations of ongoing mutations." International Journal of Online Engineering 4.1 (2008).

[42] Balamuralithara, B., and P. C. Woods. "Virtual laboratories in engineering education: The simulation lab and remote lab." Computer Applications in Engineering Education 17.1 (2009): 108-118.

[43] Tzafestas, Costas S., Nektaria Palaiologou, and Manthos Alifragis. "Virtual and remote robotic laboratory: comparative experimental evaluation." Education, IEEE Transactions on 49.3 (2006): 360-369.

[44] G Splitt, Frank. "The challenge to change: On realizing the new paradigm for engineering education." Journal of Engineering Education 92.2 (2003): 181-187.

[45] Prince, Michael J., and Richard M. Felder. "Inductive teaching and learning methods: Definitions, comparisons, and research bases." Journal of engineering education 95.2 (2006): 123-138
[46] Felder, Richard M., and Linda K. Silverman. "Learning and teaching styles in engineering education." Engineering education 78.7 (1988): 674-681.

[47] Litzinger, Thomas, et al. "Engineering education and the development of expertise." Journal of Engineering Education 100.1 (2011): 123-150.

[48] Ferris, Timothy LJ, and S. Aziz. A psychomotor skills extension to Bloom's taxonomy of education objectives for engineering education. Diss. National Cheng Kung University Tainan, 2005.

[49] Leva, Alberto, and Filippo Donida. "Multifunctional remote laboratory for education in automatic control: The CrAutoLab experience." Industrial Electronics, IEEE Transactions on 55.6 (2008): 2376-2385.

[50] Balestrino, Aldo, Andrea Caiti, and Emanuele Crisostomi. "From remote experiments to web-based learning objects: An advanced telelaboratory for robotics and control systems." Industrial Electronics, IEEE Transactions on56.12 (2009): 4817-4825.

[51] Potkonjak, V., Vukobratović, M., Jovanović, K., Medenica, M., 2010. Virtual Mechatronic/Robotic laboratory - A step further in distance learning

[52] Chen, Yuchuan, Qingni Hu, and Hong Shu. "A virtual lab for mechanical experiment based on virtools." Computer Science and Automation Engineering (CSAE), 2011 IEEE International Conference on. Vol. 3. IEEE, 2011.

[53] Newton, Sidney, et al. "THE SITUATION ENGINE: A HYPERIMMERSIVE PLATFORM FOR CONSTRUCTION WORKPLACE SIMULATION AND LEARNING." (2013)

[54] Harward, V. Judson, et al. "The iLab shared architecture: A Web Services infrastructure to build communities of Internet accessible laboratories."Proceedings of the IEEE 96.6 (2008): 931-950.

[55] Wasfy, Tamer M., et al. "Virtual training environment for a 3-axis CNC milling machine." ASME 2005 International Design Engineering Technical Conferences and Computers and Information in Engineering Conference. American Society of Mechanical Engineers, 2005.

[56] Wasfy, Tamer M., Hatem M. Wasfy, and Jeanne M. Peters. "On-line University Physics Course using Intelligent Virtual-Tutors, VirtualReality and Advanced Multimedia." ASME 2009 International Design Engineering Technical Conferences and Computers and Information in Engineering Conference. American Society of Mechanical Engineers, 2009.

[57] F. Anwar, E. Lindsay, and R. Sarukkalige, "Key factors for determining the suitability of converting a fluid-mechanics laboratory to remoteaccess mode,” Australasian J. Eng. Edu., vol. 17, pp. 11-18, 2011

[58] Garcia-Zubia, Javier, et al. "Addressing software impact in the design of remote laboratories." Industrial Electronics, IEEE Transactions on 56.12 (2009): 4757-4767.

[59] Stone, Richard T., et al. "Physical and cognitive effects of virtual reality integrated training." Human Factors: The Journal of the Human Factors and Ergonomics Society 53.5 (2011): 558-572.

[60] Barbour, Michael K., and Thomas C. Reeves. "The reality of virtual schools: A review of the literature." Computers \& Education 52.2 (2009): 402-416.

[61] Gomes, Luís, and Seta Bogosyan. "Current trends in remote laboratories."Industrial Electronics, IEEE Transactions on 56.12 (2009): 4744-4756.

[62] Anitha, D., and C. Deisy. "Deriving a prototype for the dynamic generation of learning path in an e-learning environment using genetic algorithm."International Journal of Innovation and Learning 14.1 (2013): 30-40.

[63] Santana, I., et al. "Remote laboratories for education and research purposes in automatic control systems." Industrial Informatics, IEEE Transactions on 9.1 (2013): 547-556.

[64] Müller, Dieter, and Heinz-H. Erbe. "Collaborative remote laboratories in engineering education: Challenges and visions." Advances on remote laboratories and e-learning experiences (2007): 35-59.

[65] Yeung, Herbert, David B. Lowe, and Steve Murray. "Interoperability of Remote Laboratories Systems." iJOE 6.S1 (2010): 71-80. 
[66] Santana, I., et al. "Remote laboratories for education and research purposes in automatic control systems." Industrial Informatics, IEEE
Transactions on 9.1 (2013): 547-556. 